\title{
Neuromyelitis optica associated with systemic autoimmune diseases in children
}

\author{
RA Russo*, S Tenembaum, H Arroyo and MM Katsicas
}

Address: Hospital de Pediatría Garrahan, Buenos Aires, Argentina

* Corresponding author

\author{
from $15^{\text {th }}$ Paediatric Rheumatology European Society (PreS) Congress \\ London, UK. 14-17 September 2008 \\ Published: 15 September 2008 \\ Pediatric Rheumatology 2008, 6(Suppl I):P245 doi:I0.II86/I546-0096-6-SI-P245
}

This abstract is available from: http://www.ped-rheum.com/content/6/SI/P245

(c) 2008 Russo et al; licensee BioMed Central Ltd.

\section{Case reports}

Neuromyelitis optica (NMO, Devic's disease) is a severe autoimmune disorder predominantly involving optic nerves and spinal cord [1]. Usually isolated, it has been associated with systemic autoimmune diseases in adult patients [2]. We report 2 children with a systemic autoimmune disease who developed NMO. Patients were female; NMO symptoms started at age 8 and 12 years. Patient 1 had a diagnosis of Systemic Lupus Erythematosus (SLE) (fever, cytopenias, mesangeal glomerulonephritis, positive ANA, anti-DNA, anti-Sm). She developed vomiting, tremor, hyperreflexia, paresthesia, neurogenic bladder and progressive vision loss 2 years after SLE onset. Neuroradiological investigations disclosed longitudinally extensive transverse myelitis and bilateral optic nerve involvement. Patient 2 had recurrent parotitis for 1 year before she developed vision loss, papilitis, dystonia and paresthesia. She exhibited positive ANA, anti-Ro and antiLa, and objective eye dryness. MRI evidenced lesions in brainstem and spinal cord, and evoked potentials revealed optic nerve involvement. A diagnosis of Sjögren's Syndrome (SS) associated with NMO was made. NMO-Ig was detected in both patients' sera. Intravenous and p.o. high dose steroids, a 6-month course of monthly I.V. cyclophosphamide (up to $1 \mathrm{~g} / \mathrm{m}^{2} /$ dose), followed by azathioprine (2-3 mg/Kg/day) as maintenance therapy, were used in both (plasmapheresis in one). Visual, motor and sensitive symptoms dramatically improved. Mild relapses occurred in both children; they were successfully treated with steroids. Patients are currently well, with improved vision and residual lesions in MRI.

\section{Conclusion}

NMO can occur in the setting SLE or SS in children. Intensive immunosuppressive therapy may induce remission and prevent visual loss.

\section{References}

I. Pittock SJ, Lennon VA, de Seze J, et al.: Neuromyelitis optica and non organ-specific autoimmunity. Arch Neurol 2008, 65:78-83.

2. Birnbaum J, Kerr D: Devic's syndrome in a woman with Systemic Lupus Erythematosus: diagnostic and therapeutic implications of testing for the neuromyelitis Optica IgG autoantibody. Arthritis Rheum 2007, 57:347-35I. 